\title{
Energy optimization of mechatronic systems with PMSG
}

\author{
Dariusz Tarnapowicz ${ }^{1, *}$, and Sergiej German-Galkin ${ }^{1}$ \\ ${ }^{1}$ Maritime University of Szczecin, Wały Chrobrego 1-2, 70-500 Szczecin, Poland
}

\begin{abstract}
Currently, the improvement of efficiency in electricity systems is one of the key tasks facing the industry. Due to the energy criterion, the aim of the optimization of mechatronic systems is to reduce an adverse impact of the armature in the synchronous machine and limit losses in supply lines. In recent years, autonomous generating sets with Permanent Magnet Synchronous Generator (PMSG) and ecological LNG engines are more and more often installed in power systemsThe article presents the concept of using a voltage inverter operating in the power source mode in a parallel connection with PMSG for distribution and regulation of active and reactive power
\end{abstract}

\section{Introduction}

Energy issues are decisive when designing a power plant in autonomous facilities, especially uninhabited facilities. For the reasons of optimization, various energy indicators should be taken into account, e.g. increasing system efficiency, regulation of reactive power, ensuring electromagnetic compatibility with load and power grid, etc. These issues are solved in practice thanks to advances in electromechanics, and well as semiconductor and microprocessor technologies. Nevertheless, the analysis of the problem shows that in modern energy systems, there are still unused reserves for the increase of energy efficiency when converting electromechanical energy. The greatest possibilities to increase the efficiency of electromechanical energy conversion can be obtained thanks to the optimization of operating modes of the synchronous generator. This article is devoted to solving the problem of optimization, which realizes energy-saving modes of synchronous generator's operation, in which the adverse reaction of the generator armature is limited and the efficiency of the supply lines is increased.

One of the examples of the discussed mechatronic system may be the "Shore To Ship" (STS) system - power supply of ships from land during a berth at the port. The STS system enables to reduce exhaust emission in the port and limit the costs of electricity on the ship [1],[2]. The source of electric power can be an autonomous generator set with PMSG driven by LNG gas engine [3]. The generating set is usually located far from the quay with a variable load - ship. This is caused by a limited possibility of interference in the port infrastructure.

\footnotetext{
* Corresponding author: d.tarnapowicz@am.szczecin.pl
} 
The functional scheme of the mechatronic system of a PMSG and an autonomous inverter (AI), describing in the article, is presented in Figure 1. In this case, the CSAI block is the autonomous inverter control system, and the ARL block represents the active and passive load with various parameters.

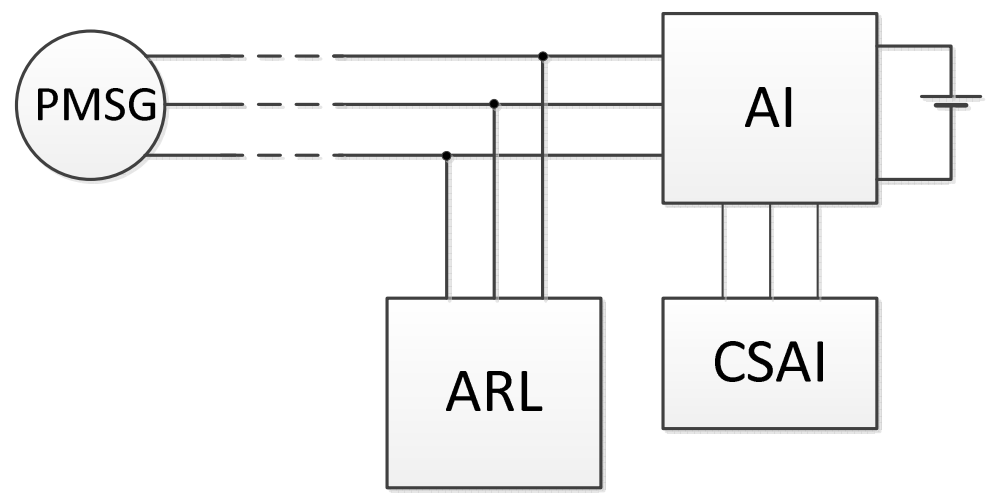

Fig. 1. Functional scheme of the PMSG and AI mechatronic system

The aspect presented in the paper is similar to the issue of using STATCOM (STATic COMpensator) and active filters. The difference is that compensation of reactive power is not the main objective, as is the case in STATCOM, but the compensation of an adverse impact of the PMSG armature.

To solve this problem it is necessary to make the analysis of the system consisting of three elements: PMSG, AI and ARL. This analysis is based on the classical theory [4],[6],[9] which arose before the development of technologies of power electronics.

The basis of analytical methods for the analysis of mechatronic systems is the theoretical study by A. Bulgakov [4], which is based on the fact that the electromagnetic and energetic properties of the inverter are determined when transferring the power from the inverter to the load. This is realized at the basic frequency, which is determined by the angular speed of the machine shaft, and the exchange of energy between passive elements takes place at the carrier frequency of transistors switched in the inverter. This exchange is accompanied by the pulsation of currents in the system, causing a slight distortion of current and additional (usually small) losses. On the basis of this analysis, typical working modes for the entire system can be described and examined.

The basis for the mathematical description of electromagnetic processes in the system (based on the basic frequency), is the spatial vector method [5], which enables the presentation of all state variables in spatial vectors in one coordinate system.

The mathematical conversion of real state variables for the system in the values of state variables in axes $d, q$ is presented by equations (1) [6], [7] for electromotive force of the machine (similarly, conversion equations are realized for voltages and currents).

$$
\left[\begin{array}{l}
e_{d} \\
e_{q}
\end{array}\right]=\frac{2}{3}\left[\begin{array}{ccc}
\cos \omega t & -\frac{1}{2} \sin \omega t & -\frac{\sqrt{3}}{2} \sin \omega t \\
-\sin \omega t & \frac{1}{2} \cos \omega t & \frac{\sqrt{3}}{2} \sin \omega t
\end{array}\right] \cdot\left[\begin{array}{l}
e_{A} \\
e_{B} \\
e_{C}
\end{array}\right]
$$

During the construction of the CSAI control block (designed to operate with a variable ARL load), the superior control of currents $I d, I q$ of the inverter is realized [8]. Electromagnetic processes in such a system can be calculated with the use of a scheme of the system shown in Figure 2. 


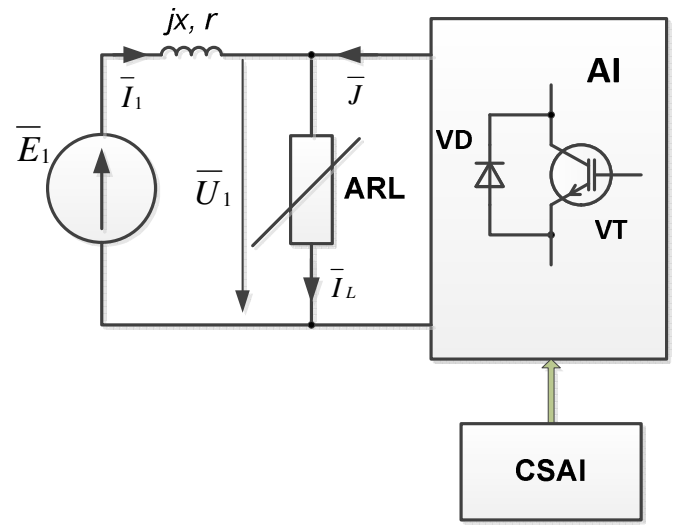

Fig. 2. Scheme for the GS and AI system with variable ARL load

PMSG was analyzed. The parameters of PMSG are presented in Table 1.

Table 1. Dew point temperature for different values of vapour pressure.

\begin{tabular}{|c|c|c|c|c|c|c|c|}
\hline $\begin{array}{c}\text { PMSG } \\
\text { Parameter }\end{array}$ & $\omega_{\mathrm{m} . \mathrm{Nom}}$ & $U_{1 . \text { Nom }}^{*}$ & $r$ & $L$ & $\ddots$ & $p$ & $m$ \\
\hline unit & $\mathrm{rad} / \mathrm{s}$ & $V$ & $\mathrm{Ohm}$ & $m H$ & $W b$ & & \\
\hline volume & 78.5 & 310 & 0.05 & 0.64 & 0.987 & 4 & 3 \\
\hline
\end{tabular}

In the scheme presented in Figure 2, the autonomous AI inverter is a controlled current source, which is connected in parallel to the ARL load and the PMSG electromotive force . Inductive reactance $x$ and resistance $r$ in the scheme are internal parameters of the generator and transmission supply line.

The mathematical description of the scheme from Figure 2 can be presented as:

$$
\begin{aligned}
& \bar{E}_{1}(t)=\bar{U}_{1}(t)+L \frac{d \bar{I}_{1}(t)}{d t}+r \bar{I}_{1}(t)+j x \bar{I}_{1}(t), \\
& \bar{I}_{L}(t)=\bar{I}_{1}(t)+\bar{J}(t)
\end{aligned}
$$

where :

$\bar{E}_{1} \quad-\quad$ EMF vector of PMSG,

$\bar{U}_{1} \quad-\quad$ voltage vector on ARL load,

$\bar{I}_{1} \quad-\quad$ current vector in the PMSG armature winding,

$\bar{J} \quad-\quad$ set current vector for the AI inverter,

$\bar{I}_{L} \quad-\quad$ current vector in the ARL load,

$r, x \quad-\quad$ resistance, reactance of stator windings.

The EMF value at the PMSG output is determined by the rotational speed of the machine shaft and the magnetic flux:

$$
\bar{E}_{1}(t)=p \omega_{m}(t) \cdot \bar{\Psi}_{0}=\omega(t) \cdot \bar{\Psi}_{0}
$$


where:

$p \quad-\quad$ number of pole pairs,

$\square_{m} \quad-\quad$ generator shaft speed,

$\overline{\Psi_{0}} \quad-\quad$ vector of magnetic flux associated.

The mathematical description of the system (2) in the coordinates $d, q$ can be presented as follows:

$$
\begin{aligned}
& E_{d}=U_{1 d}(t)+L \frac{d I_{1 d}(t)}{d t}+r I_{1 d}(t)-x I_{1 q}(t), \\
& E_{q}=U_{1 q}(t)+L \frac{d I_{1 q}(t)}{d t}+r I_{1 q}(t)+x I_{1 d}(t), \\
& I_{L d}(t)=I_{1 d}(t)+J_{d}(t), \quad I_{L q}(t)=I_{1 q}(t)+J_{q}(t)
\end{aligned}
$$

Currents $I_{l d}(t), I_{l q}(t)$ and voltage $U_{l q}(t)$ reflect the generator current $I_{l}(t)$ and $U_{l}(t)$ in axes $d, q$.

The quantities in equations (4) depend on time only in transient states. In the steady state, the system of equations (5) transforms into the form:

$$
\begin{aligned}
& E_{d}=U_{1 d}+r I_{1 d}-x I_{1 q}, \\
& E_{q}=U_{1 q}+r I_{1 q}+x I_{1 d}, \\
& I_{L d}=I_{1 d}+J_{d}, \quad I_{L q}=I_{1 q}+J_{q}
\end{aligned}
$$

The presence of a controlled current source by the change in amplitude and phase makes it possible to compensate the PMSG reactive current and (if necessary) the active current (partially), and thus optimize the efficiency of the entire system.

The examination of electromagnetic processes determined in a certain system is realized on the basis of the vector analysis for two cases:

- In the first case, the inverter compensates inductance impact of the PMSG armature realized with the use of reactive power compensation. The vector diagram for this case is shown in Figure 3, and equations (5) with $x>>r$ are transformed into the form:

$$
\begin{aligned}
& 0=U_{1 d}-x I_{1 q}, \\
& E_{1}=U_{1 q}+x I_{1 d}, \\
& I_{L d}=J_{d}, I_{L q}=I_{1 q}
\end{aligned}
$$

In this case, only active power is taken from the machine. This minimizes the armature reaction, and reactive power is taken from the inverter. It should be noted that in this case, the inverter acts as an active filter, and a capacitor may be used instead of a DC source in the inverter's power supply circuit [9], [10], [11].

- In the second case (Figure 3, b), control currents are realized so that $I_{l d}=0$, a $I_{L q}>I_{1}$. In the second case the inverter compensates inductance and resistance impact of the PMSG armature realized with the use of reactive power compensation and partially also active power compensation. Then the inverter additionally generates active power for the load and it should be powered from a DC power source. The mathematical description of the system in the case has the following form: 


$$
\begin{aligned}
& 0=U_{1 d}-x I_{1 q}, \\
& E_{1}=U_{1 q}+x I_{1 d}, \\
& I_{L d}=J_{d}, I_{L q}=I_{1 q}+J_{q}
\end{aligned}
$$

a)

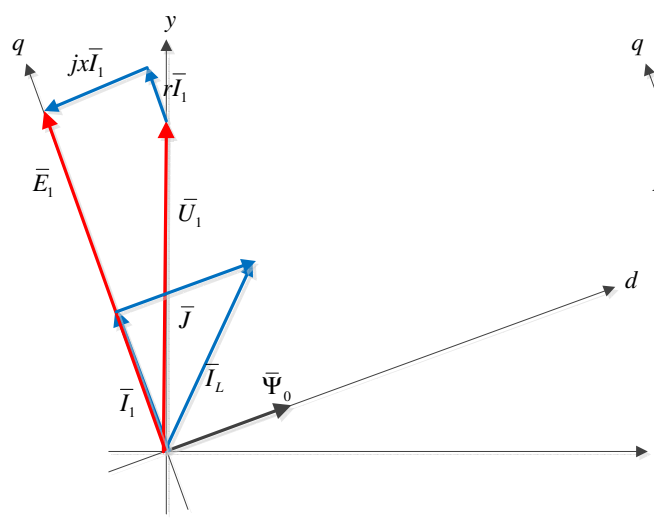

b)

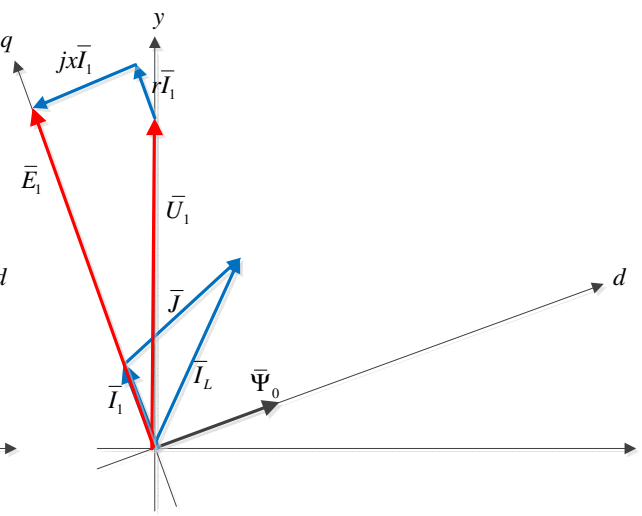

Fig. 3. Vector diagrams for PMSG and AI system with variable ARL load

Simulation researches for the mechatronic system with PMSG carried out in the MatlabSimulink environment for the above-mentioned cases. Figure 4 presents a virtual simulation model of the system with variable ARL load.

The results of the system simulation for the considered cases are presented in Figure 5, Figure 6, Figure 7 and Figure 8.

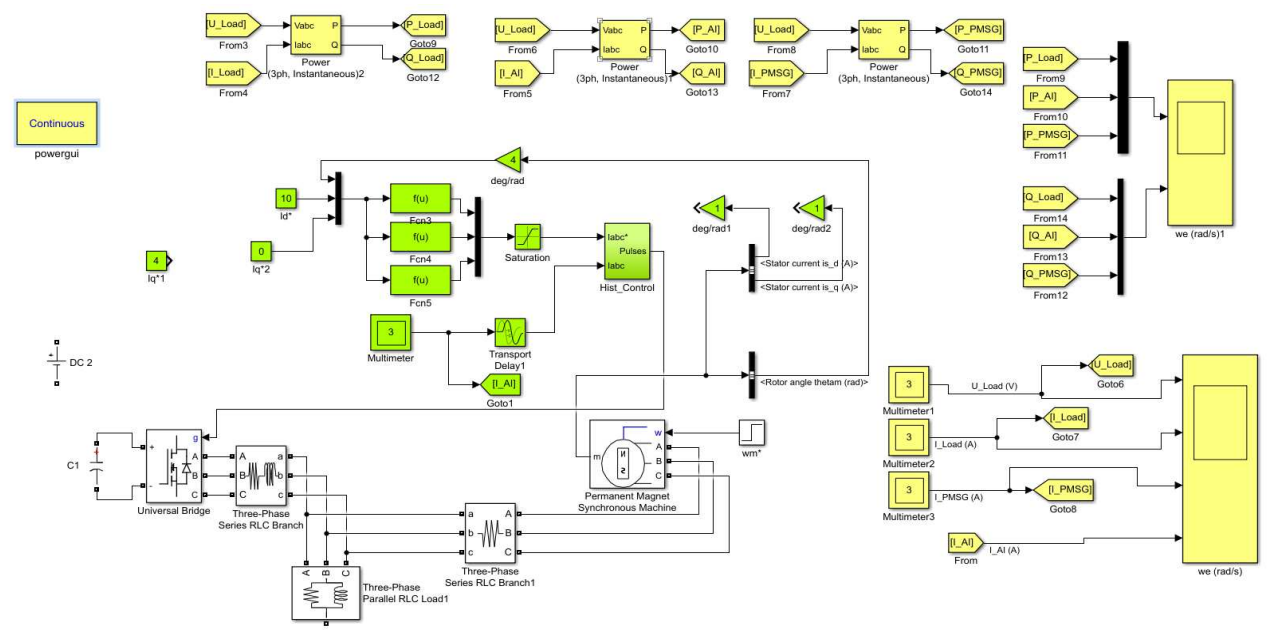

Fig. 4. Model of the mechatronic system with PMSG 

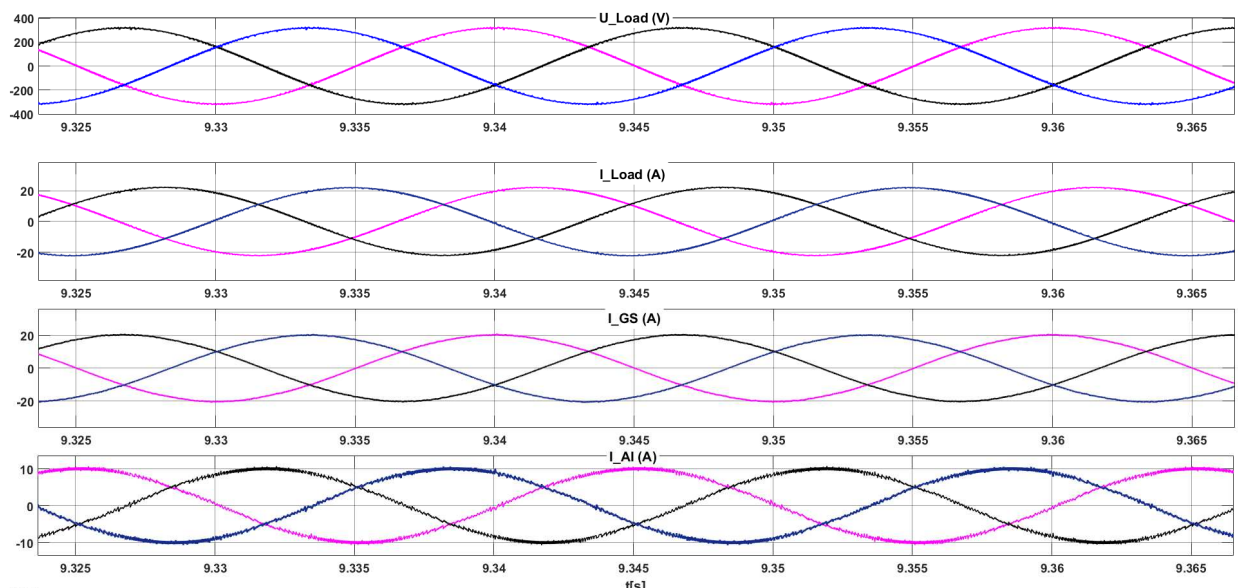

Fig. 5. Electromagnetic processes in a system with compensation of reactive power

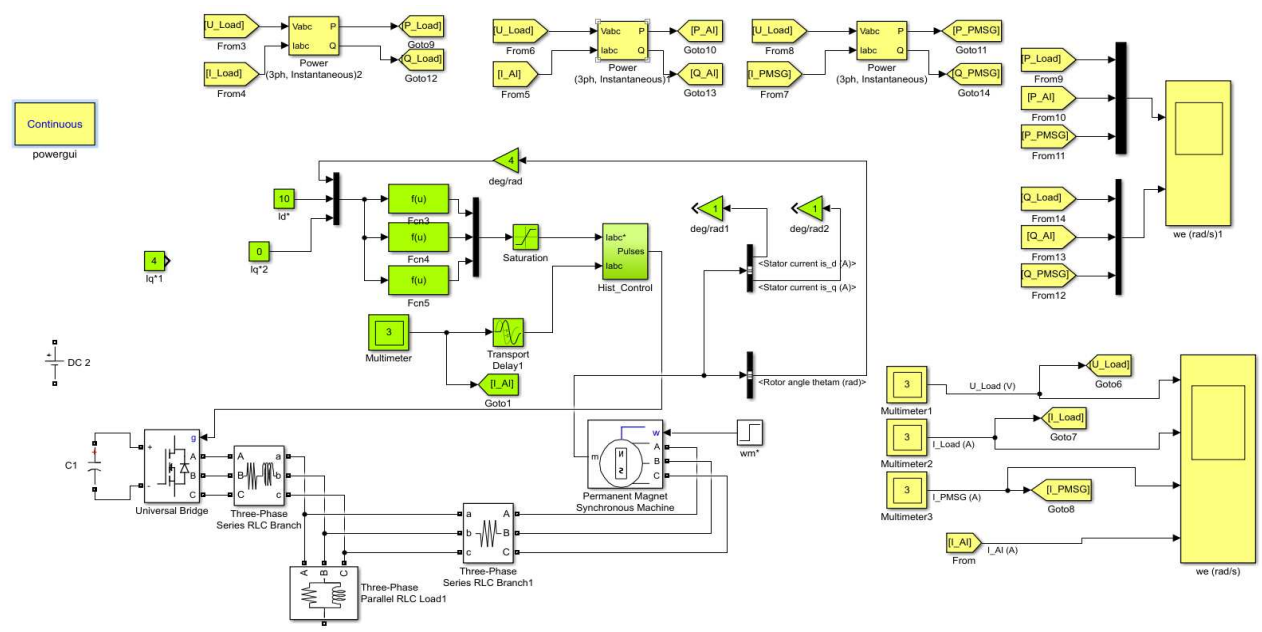

Fig. 6. Energy processes in a system with compensation of reactive power
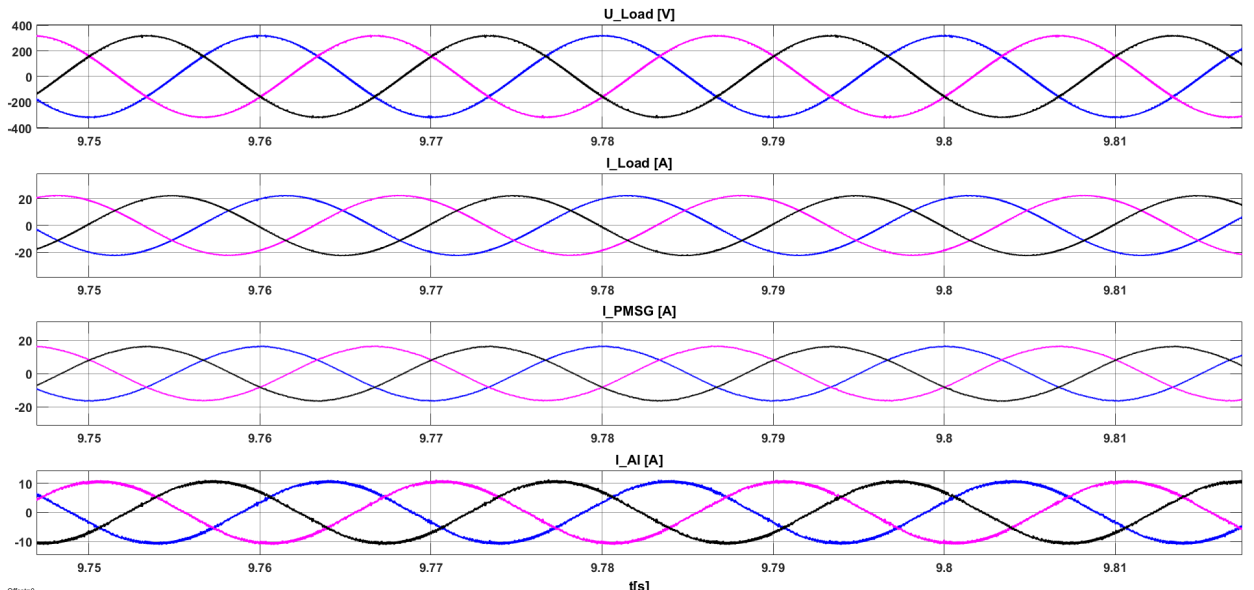

Fig. 7. Model of the mechatronic system with PMSG 

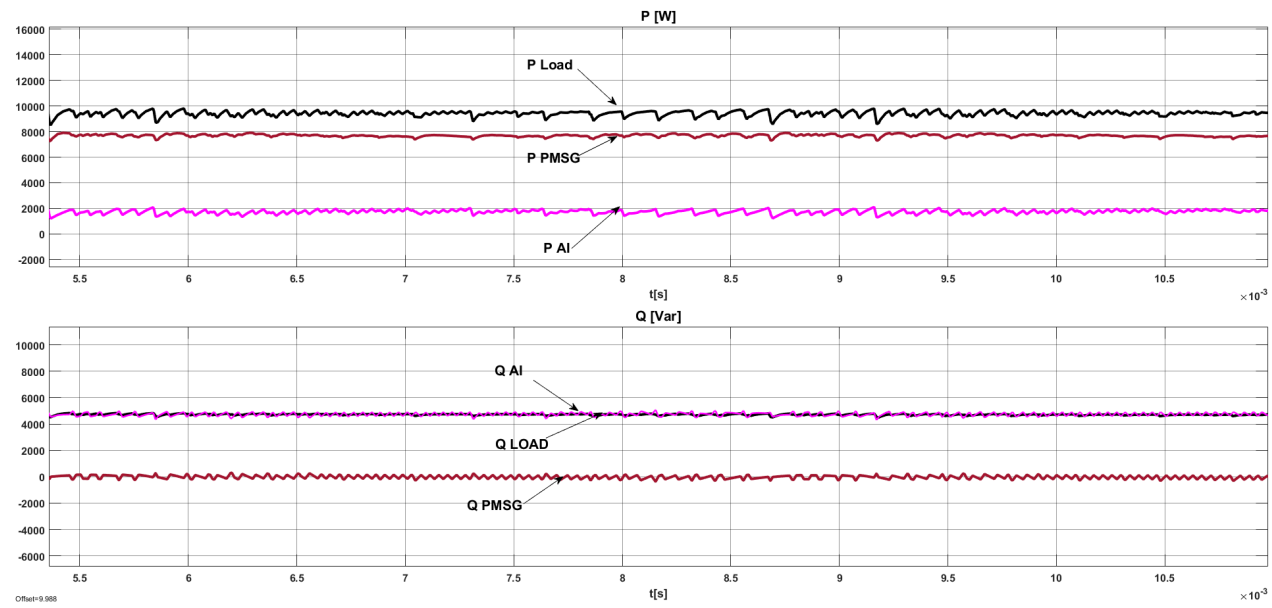

Fig. 8. Energy processes in the PMSG-AI system with compensation of reactive and active power

\section{Conclusion}

In recent years, autonomous generating sets with ecological LNG engines (example STS system) are more and more often installed in power systems. The use of a parallel active filter in the mechatronic system with PMSG (presented in the article) enabled the energy optimization of the synchronous machine and the power line. The results of simulation tests for the system confirmed the theoretical assumptions and the possibility of adjusting reactive and active power provided by PMSG.

This research outcome has been achieved under the research project: Nowoczesne technologie w systemach "Shore to Ship" No 2/S/IEiAO/16 financed from a subsidy of the Ministry of Science and Higher Education for statutory activities.

\section{References}

1. Borkowski, T., Nicewicz, G. and Tarnapowicz, D., The methodology used in defining air pollution from ships mooring in ports. Scientific Journals of the Maritime University of Szczecin. Poland, 2013, 36, 2, pp. 17-22, (2013).

2. Nicewicz, G., Sosinski, M., Tarnapowicz, D. Identification of power factor in marine electrical grid. International Multidisciplinary Scientific GeoConference-SGEM. Bulgaria, pp. 391-398, (2014)

3. Tarnapowicz, D.,German-Galkin, S:. The use of generating sets with LNG gas engines in "Shore to Ship" systems. Management Systems in Production Engineering, Poland, 3, 23, pp. 172-177, (2016)

4. Bulgakov A., A.: Novaya teoriya upravlyayemykh vypryamiteley. - M.: Nauka, Russia, pp 326, (1970)

5. Kovacs, K., Rac, I., Theil, H. Transiente Vorgänge in Wechselstrommaschinen, Verlag der Ungarischen Akademie der Wissenschaften, Budapest, Hungary, (1959)

6. Park, R.H.Tho-reaction theory of sinchronous machines. Transactions of the American Institute of Electrical Engineers, USA, 48, pp. 716 - 727, (1929)

7. Gorev A.A. Transient processes of a synchronous machine. Leningrad Nauka, Russia, 502, (1985)

8. German Galkin S. Virtual Laboratory of semiconductor systems in Matlab-Simulink wednesday. «Lan», St. Petersburg, Russia, (2013) 
9. Akagi H. et al.: Generalized theory of instantaneus reactive power in threephasecircuits. Conf. Rec. IPEC'83, Tokyo, (1993)

10. Kim, H, Blaabjerg, F., Back-Jensen, B. Instentaneous power compensation in three phase systems using p-q-r theory. IEEE Transactions on Power Electronics, USA, 17, 5, (2012)

11. Peng, F. Z., Lai, J.S. Generalized instantaneous reactive power theory for three-phase power systems," IEEE Transactions on Instrumentation and Measurement, USA, 45, pp. $293-297,(1996)$ 